\title{
CONCEITOS E FUNDAMENTOS DOS DIREITOS HUMANOS PARA PROFISSIONAIS DE ENFERMAGEM EM UNIDADE DE EMERGÊNCIA
}

\section{CONCEPTS AND PRINCIPLES OF HUMAN RIGHTS FOR NURSING PROFESSIONALS IN EMERGENCY UNIT}

\section{CONCEP'TOS Y FUNDAMENTOS DE LOS DERECHOS HUMANOS PARA LOS PROFESIONALES DE ENFERMERÍA EN LA UNIDAD DE EMERGENCIA}

\author{
Tyciana Paolilo Borges ${ }^{1}$ \\ Karla Ferraz dos Anjos ${ }^{2}$ \\ Julia Barbosa de Magalhães ${ }^{3}$ \\ Renata da Silva Schulz ${ }^{4}$ \\ Darci de Oliveira Santa-Rosa
}

Como citar este artigo: Borges TP, Anjos KF, Magalhães JB, Schulz RS, Santa-Rosa DO. Conceitos e fundamentos dos direitos humanos para profissionais de enfermagem em unidade de emergência. Rev baiana enferm. 2021;35:e38498.

\begin{abstract}
Objetivo: apreender conceitos e fundamentos sobre direitos humanos na compreensão de profissionais de enfermagem em unidade de emergência hospitalar. Método: pesquisa fenomenológica realizada com 11 profissionais de enfermagem. As entrevistas foram gravadas e a interpretação dos dados deu-se pela configuração Triádica Humanística Existencial Personalista, embasada na Declaração Universal dos Direitos Humanos. Resultados: emergiram duas categorias "Profissionais de Enfermagem conceituam os direitos tomando como referência a Declaração Universal dos Direitos Humanos" e "Profissionais de Enfermagem fundamentam a compreensão sobre Direitos Humanos em princípios bioéticos e valores". Saúde, habitação, segurança, cuidados médicos e sociais foram expressos como direitos humanos. O respeito ao outro e aos Direitos Humanos foi compreendido como independente da condição de hospitalização. Conclusão: as profissionais de enfermagem compreendem os Direitos Humanos com base na Declaração Universal dos Direitos Humanos. Os aspectos bioéticos e valores que emergiram como fundamentos para essa compreensão foram autonomia, dignidade, beneficência, alteridade e privacidade.
\end{abstract}

Descritores: Direitos Humanos. Cuidados de Enfermagem. Bioética. Emergências.

Objective: to grasp concepts and principles about human rights in the understanding of nursing professionals in a hospital emergency unit. Method: phenomenological research conducted with 11 nursing professionals. The interviews were recorded and the interpretation of the data was given by the Humanistic Existential Personalist Triadic configuration, based on the Universal Declaration of Human Rights. Results: two categories emerged "Nursing

Enfermeira. Mestre em Enfermagem. Professora da União Metropolitana de Educação e Cultura e da Universidade Salvador. Salvador, Bahia, Brasil. tycipb@hotmail.com. http://orcid.org/0000-0003-1784-6937.

Enfermeira. Doutora em Enfermagem. Professora da União Metropolitana de Educação e Cultura. Salvador, Bahia, Brasil. http://orcid.org/0000-0002-5453-8303.

Enfermeira. Universidade Federal da Bahia. http://orcid.org/0000-000 I-9294-8672.

Enfermeira. Mestre em Ciências do Cuidado em Saúde. Professora Substituta da Universidade Federal da Bahia. Salvador, Bahia, Brasil. http://orcid.org/0000-00034308-7460.

Enfermeira. Doutora em Enfermagem. Pós-doutora em Ética. Professora Adjunta da Universidade Federal da Bahia. Salvador, Bahia, Brasil. http://orcid.org/0000$0002-5651-2916$ 
professionals conceptualize rights taking as reference the Universal Declaration of Human Rights" and "Nursing professionals base their understanding of Human Rights on bioethical principles and values". Health, housing, safety, medical and social care were expressed as buman rights. Respect for the other and human rights was understood as independent of the condition of hospitalization. Conclusion: nursing professionals understand human rights based on the Universal Declaration of Human Rights. The bioethical aspects and values that emerged as principles for this understanding were autonomy, dignity, beneficence, otherness and privacy.

Descriptors: Human Rights. Nursing Care. Bioethics. Emergencies.

Objetivo: aprehender conceptos y fundamentos sobre los derechos humanos en la comprensión de los profesionales de enfermería en una unidad de emergencias hospitalarias. Método: investigación fenomenológica realizada con 11 profesionales de enfermería. Las entrevistas fueron grabadas y la interpretación de los datos fue dada por la configuración Tríadica Humanista Existencial Personalista, basada en la Declaración Universal de Derechos Humanos. Resultados: surgieron dos categorías "Los profesionales de enfermería conceptualizan los derechos tomando como referencia la Declaración Universal de Derechos Humanos" y "Los profesionales de enfermeria basan su comprensión de los Derechos Humanos en principios y valores bioéticos". La salud, la vivienda, la seguridad, la atención médica y social se expresaron como derechos humanos. El respeto por el otro y los derechos humanos se entendía como independiente de la condición de hospitalización. Conclusión: los profesionales de enfermería entienden los derechos humanos sobre la base de la Declaración Universal de Derechos Humanos. Los aspectos bioéticos y los valores que surgieron como fundamentos para este entendimiento fueron la autonomía, la dignidad, la beneficencia, la alteridad y la privacidad.

Descriptores: Derechos Humanos. Cuidado de Enfermería. Bioética. Emergencias.

\section{Introdução}

A Declaração Universal dos Direitos Humanos (DUDH), criada e implementada pela Organização das Nações Unidas (ONU) em 1948, está pautada em direitos civis, sociais, culturais, econômicos e políticos e abrange todos os povos de todas as nações, e independentemente de qualquer condição humana, cabe aos indivíduos e a cada órgão da sociedade promover o respeito a esses direitos e liberdades ${ }^{(1)}$. Essa declaração consolidou a construção de inúmeros documentos para assegurar os direitos das pessoas, dentre eles, a Constituição da República Federativa do Brasil, promulgada em $1988^{(2)}$.

Em 1953, o Conselho Internacional de Enfermeiras(os) (CIE) aprovou o Código Internacional de Ética para Enfermeiras(os) que apresenta em seu preâmbulo quatro responsabilidades fundamentais: promover e restaurar a saúde, prevenir a doença e aliviar o sofrimento. O código visa atender às necessidades de Enfermagem no âmbito universal, em respeito aos Direitos Humanos (DH) que são inerentes à profissão. Para tanto, os cuidados devem ser prestados sem distinção de qualquer natureza e proporcionar serviços de qualidade à saúde da pessoa, família e comunidade, além de coordenar suas atividades de modo interdisciplinar ${ }^{(3)}$.

Nas relações de cuidado na saúde, especialmente na Enfermagem, faz-se necessário que a enfermeira tenha contato com os instrumentos internacionais (e nacionais) de Direitos $\mathrm{Hu}-$ manos que influenciam a implementação de políticas de saúde e pesquisa em saúde ${ }^{(4)}$, o que contribuirá para a compreensão desses direitos, contemplados também no Código Internacional de Ética para Enfermeiras(os), garantindo, assim, o respeito e a proteção dos Direitos Humanos.

A compreensão sobre Direitos Humanos pelas profissionais de Enfermagem é fundamental à medida em que se busca uma prática mais humanizada e resolutiva. Ao compreender a temática, amplia-se as possibilidades das profissionais reconhecerem as singularidades humanas expressas no contexto social, político, econômico e cultural, e as diversidades da existência humana é parte de uma proposta de transformação social no cuidado em saúde ${ }^{(5)}$.

Ao acumular saberes, incluindo conceitos e fundamentos dos Direitos Humanos, a Enfermagem pode conduzir práticas de cuidado 
balizadas em fundamentos humanistas em contextos de vulnerabilidade e de violação aos Direitos Humanos. A Enfermagem, ao ampliar suas perspectivas sobre a existência humana, adotando postura ética compatível com a defesa aos direitos e liberdades, além da não discriminação, consegue superar os desafios do seu cuidado, especialmente em situações de vulnerabilidade ${ }^{(5)}$.

Para os diferentes contextos, o setor de emergência é relevante, e foi o ambiente escolhido para este trabalho, pois sua cobertura é universal à saúde e exige qualidade na integração entre os sistemas pré-hospitalares e os recursos disponíveis para atender a população nas suas necessidades, seja em quantidade suficiente de pessoas treinadas, materiais e medicamentos essenciais ${ }^{(6)}$. A estrutura da emergência deve estar baseada em direitos para atendimento de emergência não discriminatório, além da supervisão e autoridade adequadas para fazer cumprir essas leis nesse tipo de ambiente.

A escassez de produções na Enfermagem sobre abordagens que integram os Direitos $\mathrm{Hu}-$ manos e o cuidado em saúde pode favorecer reflexões limitadas sobre a prática de cuidado humano e resolutivo, especialmente em condições de vulnerabilidade. Estudo sugere que novas pesquisas sejam importantes para analisar as práticas da Enfermagem, com o intuito de consolidar o conhecimento sobre Direitos $\mathrm{Hu}$ manos para Enfermagem ${ }^{(4)}$.

Assim, este estudo também busca evidenciar que a falta da compreensão sobre dignidade nas relações de cuidado na Enfermagem gera confusão e ambiguidade, que implica em inconsistência na prática e incompatibilidade para elaborar ou definir conceitos que possam ser operacionalizados, visto que há necessidade, por parte da Enfermagem, de reformular o estudo e a promoção da dignidade ${ }^{(7)}$. Desse modo, provoca a profissional a aprofundar o conhecimento e a compreensão dos Direitos Humanos.

Nessa perspectiva, a relevância do presente estudo dá-se pela carência de investigações que demonstram o entendimento das profissionais de Enfermagem sobre os Direitos Humanos, em especial no contexto hospitalar nos setores de emergência. Dessa forma, ampliar a compreensão sobre esta temática possibilita a reflexão da equipe de Enfermagem sobre a importância dos Direitos Humanos ao prestar os cuidados para tornar a assistência mais humanizada e ética.

Baseado na compreensão sobre os direitos das pessoas, as profissionais de Enfermagem precisam tomar decisões que se alicercem na DUDH e na Carta dos Direitos dos Usuários da Saúde, no intuito da preservação da dignidade humana.

Dessa forma, definiu-se como objetivo do presente estudo apreender conceitos e fundamentos sobre Direitos Humanos na compreensão por profissionais de Enfermagem em unidade de emergência hospitalar.

\section{Método}

Pesquisa fenomenológica, realizada mediante a compreensão de enfermeiras e técnicas de enfermagem sobre conceito e fundamentos dos Direitos Humanos, com base na realidade que vivenciam em um hospital público de Salvador, Bahia. Foi utilizada a fenomenologia, pois essa técnica preocupa-se em buscar, na consciência das pessoas e por meio de suas experiências, como o conhecimento é construído, tendo como objeto o mundo vivido pelo sujeito ${ }^{(8-9)}$.

Este estudo é parte integrante da dissertação de mestrado intitulada "Direitos Humanos vivenciados pelos profissionais de Enfermagem no cuidado à pessoa hospitalizada", que compreendeu como as(os) profissionais de Enfermagem vivenciam o respeito aos Direitos Humanos no cuidado à pessoa hospitalizada. Assim, desvela-se os significados das expressões de tais experiências ao evidenciar a estrutura do fenômeno.

O lócus de estudo foi um hospital de grande porte da rede pública do estado da Bahia, localizado no município de Salvador, com atendimento contínuo nas 24 horas à população da capital e do interior, exclusivamente pelo Sistema Único de Saúde (SUS).

Participaram do estudo 11 profissionais de Enfermagem, três enfermeiras, cinco técnicas e três 
técnicos de enfermagem, que atuam no cuidado aos usuários da saúde na unidade de emergência do hospital. Todas foram abordadas presencialmente, durante o horário de trabalho, e selecionadas conforme a escala diária e disponibilidade, não havendo relação entre a pesquisadora e as participantes antes do início do estudo. Ressalta-se que, mesmo havendo três participantes do sexo masculino, utilizou-se enfermeiras e técnicas de enfermagem, pois o sexo feminino foi majoritário entre os profissionais e, também, por questões de gênero na enfermagem.

Os critérios de inclusão foram: atuar na assistência de Enfermagem em hospital público da rede do SUS, ser formada há pelo menos dois anos e atuar no período diurno. Não obstante o setor de emergência não ter sido critério de inclusão, todas as participantes atuavam nesse local. Foram excluídas do estudo: as profissionais de enfermagem que estavam em período de férias, folga nos dias da coleta de dados, afastadas por problemas de saúde ou capacitação, ou por não terem disponibilidade para a entrevista fenomenológica.

A entrevista fenomenológica foi feita mediante a aproximação da pesquisadora com as pessoas que vivenciam o fenômeno, pois só elas podem fornecer os dados necessários para compreensão do objeto em investigação. A entrevista foi guiada por um roteiro previamente elaborado pelas pesquisadoras, composto por dados de caracterização das participantes e norteada pela questão "O que você entende sobre direitos humanos?" Estas participantes, por sua vez, foram questionadas na condição de profissional de Enfermagem.

A investigadora procurou entrar no mundo das experiências vividas pelas depoentes, deixando-as livres para responder a pergunta, sem interrompê-las, e com o tempo necessário. As entrevistas foram realizadas pela pesquisadora principal, em local privativo, sem barulhos ou interrupções de terceiros, escolhido pelas participantes que aceitaram o convite e assinaram o Termo de Consentimento Livre e Esclarecido (TCLE).
Para garantir a fidelidade dos dados na transcrição foi utilizado o gravador de áudio, após autorização para o seu uso. Ao final da gravação, a pesquisadora permitiu às participantes ouvirem todo o áudio para confirmação, acréscimo ou exclusão de quaisquer relatos.

Após a coleta dos dados, as respostas fornecidas pelas participantes da pesquisa foram transcritas na íntegra, acrescentando-se um número de ordem às categorias profissionais, Enfermeira (ENFA) e Técnicas de Enfermagem (TE), para garantir o anonimato. Posteriormente, os números de ordem foram substituídos por nomes de flores, como pseudônimos, escolhidos por meio da associação dos seus significados com a essência dos depoimentos das participantes.

A análise dos dados foi guiada pela configuração Triádica Humanística-Existencial-Personalista que possibilitou a apreensão da essência dos depoimentos das participantes ${ }^{(10)}$. Esse tipo de análise foi utilizado com base nas informações fornecidas pelas entrevistadas, sistematizando seus conteúdos e expressões. Após essa análise, construiu-se a estrutura do fenômeno, emergindo uma temática e duas categorias.

Portanto, para a análise dos dados e sua posterior interpretação, foram seguidos sete $\operatorname{passos}^{(10)}$ :

a) leitura atenta do conteúdo total expresso pelas enfermeiras e técnicas de enfermagem, de forma a apreender o seu significado dentro da estrutura global;

b) releitura do texto para identificação de Unidades de Significado;

c) apreensão do conteúdo verbal expresso pelas participantes dos aspectos significativos de suas percepções, para compreensão e análise de suas vivências. Estas unidades foram apreendidas por meio de um processo mental analítico-associativo, fundamentado no referencial teórico dos direitos humanos, dos princípios bioéticos e nos valores;

d) identificação e classificação dos aspectos que apresentavam convergências de conteúdo de vários depoimentos expressos 
por diferentes participantes, procurando aquilo que se mostrava constante nas falas de cada uma;

e) agrupamento das locuções de efeito ou de seus significados para a construção das categorias temáticas;

f) apresentação da estrutura do fenômeno com a temática;

g) análise compreensiva dos dados significativos das categorias da temática, tendo como base a interpretação do conteúdo associado ao referencial dos Direitos $\mathrm{Hu}$ manos, princípios bioéticos e valores.

O presente estudo utilizou como referencial teórico a Declaração Universal dos Direitos Humanos e a Constituição da República Federativa do Brasil ${ }^{(1-2)}$, além da Declaração Universal sobre Bioética e Direitos Humanos, de 2005, e a Carta de Direitos dos Usuários do SUS, elaborada pelo Ministério da Saúde desde $2006^{(11-12)}$.

A eticidade da pesquisa foi assegurada buscando atender às exigências éticas da Resolução do Conselho Nacional de Saúde n. 466, de $2012^{(13)}$, que regulamenta a pesquisa com seres humanos. O projeto foi aprovado pelo Comitê de Ética em Pesquisa da Escola de Enfermagem da Universidade Federal da Bahia, sob Parecer n. 932.998/2014 e CAAE no 37557214.6.0000.553.

\section{Resultados}

Participaram 11 profissionais de Enfermagem, oito do sexo feminino e três do sexo masculino, de 31 a 52 anos de idade, com média de 41 anos. O tempo de formação variou entre $10 \mathrm{e}$ 31 anos. Com relação ao tempo de atuação na instituição de saúde, a distribuição ficou heterogênea, entre 2 e 31 anos. No quesito titulação/cursos, seis possuíam especialização ou cursos na área hospitalar e um técnico de enfermagem era graduado em Teologia e Filosofia.

Após as entrevistas, fundamentadas no referencial dos Direitos Humanos e da bioética, foi possível apreender os sentidos e os significados das participantes para a construção das duas categorias empíricas e da temática que estrutura o fenômeno situado, a saber: Temática "Conceitos e fundamentos dos Direitos Humanos expressos por profissionais de Enfermagem em unidade de emergência"; Categoria 1 "Profissionais de Enfermagem conceituam os direitos tomando como referência a Declaração Universal dos Direitos Humanos"; Categoria 2 "Profissionais de Enfermagem fundamentam a compreensão sobre Direitos Humanos em princípios bioéticos e valores".

\section{Temática: Conceitos e fundamentos dos Direitos Humanos expressos por profissionais de Enfermagem em unidade de emergência}

A temática constituiu-se da análise compreensiva das duas categorias emergidas, tendo como referência as Unidades de Significado dos depoimentos das participantes do estudo que atuam em unidades de emergência de hospital sobre os Direitos Humanos relacionadas às suas vivências com a Declaração Universal dos Direitos Humanos, os princípios da bioética e valores.

\section{Categoria 1: Profissionais de Enfermagem conceituam os direitos tomando como referência a Declaração Universal dos Direitos Humanos}

As profissionais de Enfermagem que atuam em unidades de emergência hospitalar expressaram suas conceituações sobre os Direitos Humanos fundamentado na Declaração Universal dos Direitos Humanos, como o direito da pessoa à saúde, à habitação, aos cuidados médicos, aos cuidados sociais, ao direito de ir e vir, à dignidade da pessoa humana, cidadania, legislação, direitos básicos e ordem social.

Para as enfermeiras e técnicas de enfermagem, os Direitos Humanos se constituem no respeito e na valorização da pessoa, sem restrições sociais, e devem ser assegurados. Estes garantem o respeito ao cidadão e à sua dignidade; seu desrespeito interfere no sentimento de dignidade. Os Direitos Humanos são o respeito mútuo, com a inclusão dos direitos civis, sociais e culturais, e a cidadania é um fundamento. 
Direitos Humanos é você respeitar essa pessoa independente da condição dele, que ele esteja. É a valorização e o respeito à pessoa independente do credo, independente da sua condição social, independente do que ele seja pra sociedade. (Frésia).

É o direito de todo cidadão de ser tratado com respeito [...] É você ter o direito à vida [...] com dignidade. (Girassol).

É assegurado à pessoa. (Orquídea).

São noções que auxiliam o cidadão a respeitar uns aos outros. (Dália).

Inclui direitos civis, sociais, culturais, entre outros. (Bromélia).

Se todo ser humano tivesse seus direitos respeitados se sentiriam mais dignos. Acho que muitas vezes falta um pouco isso, não somente na área de saúde, na verdade, no contexto geral. (Magnólia).

Os valores como saúde, habitação, segurança, cuidados médicos e sociais foram expressos como Direitos Humanos, enfatizando que os usuários têm direito à saúde, de serem esclarecidos sobre os seus direitos, que as profissionais de Enfermagem devem atender de maneira rápida, e todo ser humano, enquanto cidadão, tem direito à assistência de qualidade. Além disso, as pessoas têm o direito de ir e vir, estudar, trabalhar, ter casa própria, ter saúde de qualidade, aspectos que constituem os Direitos Humanos, entretanto têm-se observado o desrespeito desses direitos.

Então o cliente nosso ele tem o direito à saúde e nós procuramos dar esse direito da forma mais rápida possível para ele. (Urze).

Todo ser bumano tem direito a uma assistência de qualidade sem jogo de empurra, buscando pelos seus direitos como cidadão. (Cravo)

Sendo atendido as suas prioridades vitais, principais, como saúde, educação, moradia, segurança, lazer também faz parte, e direito a esclarecimento, de tudo que acontece na nossa sociedade que às vezes o cidadão é totalmente albeio até aos seus próprios direitos. (Girassol).

Todo ser bumano tem direito de ir e vir, estudar, trabalhar, ter sua casa própria, não ser discriminado, e saúde de qualidade sem burocracia. (Cravo).

Temos várias questões: negro, discriminação, pobre que às vezes está mal vestido, aí ele tem direito de ir e vir, de entrar em qualquer instituição, mas muitas vezes é barrado por conta dos trajes, então não é respeitado, então a falta desse direito é um desrespeito. (Magnólia).

Enfermeiras e Técnicos de Enfermagem compreendem os Direitos Humanos como leis, que garantem benefícios aos mais necessitados.
Esses direitos são relevantes para a vida em sociedade e para que o seu atendimento imediato não dependa dos profissionais da área de saúde.

Entendo que os Direitos Humanos é o conjunto de leis que vêm para beneficiar aquele que está necessitando no momento. (Açafrão).

São todos os direitos que são na verdade são garantidos por Lei [...] Direitos relevantes, que são necessários realmente para que você tenha uma vida em sociedade e você consiga sobreviver de maneira harmônica com o meio ambiente. (Rosa Champanhe).

Claro que existem choques, porque as pessoas acham que ter o direito ele é imediato, mas nem sempre a gente consegue fazer que esse direito seja imediatamente atendido, não por falta de desejo, mas por falta da própria acomodação o que não depende dos profissionais da área da saúde. (Gerbera).

\section{Categoria 2: Profissionais de Enfermagem}

fundamentam a compreensão sobre Direitos Humanos em princípios bioéticos e valores

Nesta categoria, as profissionais de Enfermagem da unidade de emergência fundamentaram sua compreensão sobre os Direitos Humanos tendo em vista os princípios bioéticos e valores, como autonomia, dignidade, universalidade, beneficência, alteridade, respeito, direito do usuário e privacidade. Além disso é desvelado os princípios, como autonomia e autodeterminação, ao cuidar do usuário.

O respeito à autonomia teve maior frequência nos depoimentos das enfermeiras e técnicas, e a vivência dos Direitos Humanos se expressa na escolha. Dessa forma, é compreendido pela equipe que os usuários têm o direito de decidir sobre o seu cuidado e a terapêutica em relação ao seu processo de adoecimento, para isso há necessidade de habilidades para a comunicação entre profissionais e usuários. Foi desvelado ainda que existe maior autonomia das profissionais e dos usuários quando em instituições privadas.

Incluindo e respeitando a sua opinião em relação às terapêuticas que é aplicada nele, como o direito de decidir se aceita ou não. O que é instituído para ser realizado no seu corpo, em relação a sua saúde [...] Que ele tenha sua livre escolha. Que ele possa decidir pelo seu tratamento. Muitas vezes o paciente recusa, então a gente tem que ter uma habilidade de explicar pra ele a necessidade do tratamento. (Girassol). 
Porém, muitas vezes nossa população ela não é também muito bem esclarecida com relação a isso. A instituição particular nos dá um respaldo maior em fazer [...] em conseguir fazer algo mais para o paciente. (Gerbera).

Para vivenciar os Direitos Humanos tem que se fazer o que gosta. (Cravo).

A dignidade, como princípio de defesa da vida, é fundamental na compreensão sobre os Direitos Humanos. Houve a compreensão que o respeito ao ser humano independe das condições da pessoa e faz parte da dignidade do ser humano. O princípio da universalidade garante os Direitos Humanos pelo Estado e há empenho da área da saúde para o atendimento a esses direitos, porém falta dedicação dos próprios profissionais.

Nos serviços, precisa manter o mínimo de dignidade de serviço na área. (Urze).

Que ele [usuário] é uma pessoa que está ali independente das suas condições, nós temos tentado. Não é fácil, nós temos tentado cuidar dessa pessoa como ser bumano, eles às vezes se armam, até a própria família mesmo [...] Também tem a questão do morador de rua, nós trabalhamos com morador de rua, e assim, é uma necessidade que a gente tem de mostrar para ele que também que ele é importante. Mas o respeito dele como ser humano, como pessoa, independente de qualquer coisa que ele seja ou que a sociedade esteja estigmatizando ele (cor, raça, religião) até aquela questão, a marginalização, que sejam marginalizados as pessoas querem entender como se não fosse um ser bumano. (Frésia).

Garantir, né? Seus direitos. Perante o Estado e perante as outras pessoas também [...] por falta de profissionais [pausa] desempenhados, né? Em assegurar esses direitos. (Orquídea).

Então, acredito que a área da saúde tenha esse lado de serviço, de dedicação e o trabalbador do SUS tem esse grande desafio: de estar sempre lutando para que mais pessoas sejam bem atendidas. (Urze).

Foram mencionados na entrevista os princípios da bioética, como a beneficência. Há esforço das profissionais para darem o melhor de si face à necessidade do usuário e, ao mesmo tempo, zelar pelos Direitos Humanos, ao respeitar o direito ao acompanhante, como forma de auxílio ao usuário no aceite do seu tratamento.

Mas temos que tentar sempre dar o melhor da gente pra poder prestar uma melhor qualidade. Naquilo que o paciente naquele momento está precisando. Acho que esse é o momento de você fazer valer esses direitos que ele tem, prestando esse serviço para ele, de dar a melhor assistência no momento que ele mais está precisando. (Açafrão).

E quando ele vê o acompanhante dele ali feliz e sorrindo, ele começa a aceitar melhor o tratamento e se sente um pouco em casa e isso termina melhorando o tratamento. (Frésia).

Quanto ao atendimento dos Direitos Humanos, as profissionais de Enfermagem consideram a alteridade como princípio fundamental, o exercício de se colocar no lugar do outro. O respeito constitui-se um valor essencial, e é visto como fundamento que independe da condição de hospitalização do usuário. O direito à informação e o respeito à privacidade dos usuários é considerado como essencial pela equipe de Enfermagem.

Muitas vezes ele passa por situações que não [...] não é
uma situação boa pra nenhum ser humano. (Orquídea).

A vivência desses Direitos Humanos ela vem de acordo com o cuidar do próximo, como se fosse alguém realmente seu. (Açafrão).

O respeito ao próximo, mesmo estando bospitalizado ou não. (Gerbera).

Para mim todas essas condutas a gente está respeitando os Direitos Humanos. (Rosa Champanhe).

E na minha atuação em si eu procuro está tentado fazer valer esse direito do paciente. E também muitas vezes justamente por não conbecer, por não ser esclarecido sobre procedimentos, sobre sua necessidade. (Girassol).

Do respeito à privacidade, mesmo na instituição, às vezes no hospital lotado a gente luta para manter a privacidade da pessoa para que ela não fique exposta. (Frésia).

\section{Discussão}

A compreensão das profissionais de Enfermagem sobre Direitos Humanos perpassa pelos direitos individuais. As profissionais compreendem que os DH são leis que garantem benefícios aos mais necessitados, diferente do que é expresso na Declaração Universal dos Direitos Humanos, na qual todos os seres humanos são iguais perante a lei, sem qualquer distinção, independentemente de suas necessidades, ou seja, garante os direitos de forma universal e igualitária e não só equitativa. De igual modo, Direitos Humanos reflete em "[...] direitos inerentes a todos os seres humanos, independentemente de raça, sexo, nacionalidade, etnia, idioma, religião ou qualquer outra condição" ${ }^{(1: 2)}$. Nesse sentido, os direitos individuais são incluídos por ordenamento jurídico, expressos pelos direitos civis, 
sociais, econômicos, políticos e culturais e não são exclusivos a um grupo específico.

Os direitos sociais expressos, como a saúde e a educação, além do direito de ir e vir, trabalhar, morar, direito à assistência de qualidade, à segurança, aos cuidados médicos e de ser esclarecido, também foram citados como Direitos Humanos neste estudo. Para as profissionais, esses direitos estão fundamentados na cidadania e respaldado na DUDH, na qual estão incluídos o direito à vida, à liberdade, à educação, ao trabalho, à reparação, à proteção social. Para além desses direitos, a saúde envolve uma vida digna com ambiente equilibrado ${ }^{(14)}$.

Desse modo, ao refletir sobre os direitos humanos, deve-se entender que estes envolvem uma rede complexa de assistência, que são representados por todos os direitos expressos nas falas das participantes deste estudo. Destarte, os DH envolvem uma vida digna com ambiente equilibrado $^{(14)}$, em que é resguardado o direito à segurança em caso de desemprego, doença, invalidez, viuvez, velhice ou outros casos de perda dos meios de subsistência ${ }^{(15)}$.

Entretanto, este estudo revela o desrespeito dos DH na assistência à saúde expresso nos depoimentos das participantes, no atendimento ao usuário da saúde, apesar do esforço apresentado para atender o paciente nas suas necessidades. Foi possível apreender que o esclarecimento de dúvidas sobre os procedimentos nem sempre é realizado em tempo oportuno, o que pode gerar atrito entre familiares e os próprios pacientes. Os profissionais de saúde, por serem multiplicadores de informações, atuam como facilitadores no processo de consolidação dos direitos por meio do envolvimento entre os usuários e familiares ${ }^{(16)}$, o que contribui na minimização dos entraves encontrados na garantia e no respeito aos Direitos Humanos, incluindo o direito de esclarecimento.

O direito de ser esclarecido foi compreendido pelas profissionais como direito dos usuários que buscam os serviços de emergência. Desse modo, o usuário deve ser informado, com linguagem e meio de comunicação adequados, sobre os serviços e ações propostos para assistência e tratamento da saúde, com minimização de riscos e intercorrências acerca da assistência de Enfermagem prestada ${ }^{(17)}$.

O estudo ainda revela que é dever das profissionais de Enfermagem prestar atendimento rápido nos casos de emergência, de forma adequada, com qualidade e no tempo certo ${ }^{(18)}$. Desse modo, mesmo diante de setores como o da emergência, é dever da equipe de Enfermagem assegurar a continuidade da assistência e a segurança do paciente nas situações adversas ${ }^{(17)}$. Conhecer os direitos das pessoas à saúde, assegurar uma assistência ágil, eficaz, segura e de qualidade é indispensável aos profissionais de Enfermagem, sobretudo por estar fundamentado em normativas. Nesse sentido, compreender, valorizar e respeitar os DH, independente das adversidades nos diversos ambientes de cuidado, constitui-se um valor essencial à vida, entendido como um direito fundamental presente na Constituição Federal Brasileira ${ }^{(2)}$ e no Código de Ética dos Profissionais de Enfermagem ${ }^{(17)}$.

Além disso, nas relações de cuidado com o usuário e sua família, as profissionais de Enfermagem devem considerar as capacidades individuais e de grupo, ter disposição para garantir um bom atendimento ao beneficiar mais pessoas, em qualquer contexto, com qualidade na sua assistência, a fim de promover acolhimento às necessidades individuais e instruir a busca adequada pelos seus direitos.

Vale destacar que os Direitos Humanos são fundamentados nos princípios bioéticos e valores $^{(19)}$, e este estudo revelou que, dentre os princípios da bioética, a autonomia foi a mais expressiva entre as profissionais que vivenciam o respeito à autonomia do usuário nas relações de cuidado, usando, em parte, a comunicação eficaz. Desvelam ainda que a autonomia profissional favorece a tomada de decisões referentes aos cuidados ao usuário nas organizações privadas. Destarte, emergiu o direito de recusa dos usuários aos procedimentos, mesmo após o esforço de tentar beneficiar o cidadão ao explicar os riscos de complicações de tais ações.

Estudo revela que a "[...] procura por respostas sobre a dimensão humana do cuidado tem aumentado pelos profissionais da saúde, preocupados com relações de autonomia, justiça 
e respeito ao ser humano"(16:5), revelando a importância de se garantir o respeito à autonomia dos usuários que são atendidos nos serviços de saúde, especialmente no ambiente de emergência hospitalar.

A dignidade e o respeito, princípios também bioéticos, foram expressos pelas Enfermeiras e Técnicas de Enfermagem que independe das condições de hospitalização, constituindo-se assim em valores. O princípio da universalidade foi expresso como fundamento dos $\mathrm{DH}$, garantido pelo Estado, e que não estão assegurados por falta de dedicação dos próprios profissionais, mesmo revelado empenho da área de saúde para garantia desse princípio. Com o intuito de amenizar tais consequências, os profissionais devem observar e estar atentos durante a sua prática assistencial, no ambiente hospitalar, na busca de violações reais ou potenciais dos DH dos usuários, da equipe e de outros trabalhadores ${ }^{(20)}$, e assim promover um ambiente seguro, com atendimento universal e favorável para a garantia da dignidade e do respeito aos Direitos Humanos.

Para o princípio da beneficência destaca-se que as profissionais se esforçam e oferecem o melhor de si para atender a necessidade do usuário em benefício da saúde ao incluir a família nesse contexto. Na compreensão das participantes, a alteridade surgiu como forma de atender aos Direitos Humanos, sendo este um princípio fundamental, pois expressaram identificar e reconhecer as singularidades de quem está sendo cuidado, mesmo diante das diferenças pessoais ${ }^{(19)}$.

Para além da alteridade, a privacidade emergiu como valor essencial para a compreensão dos direitos da pessoa que se encontra hospitalizada, já que o respeito à privacidade do usuário da saúde deve ser considerada e assegurada na prestação de cuidados pela Enfermagem, assim como configura-se como uma obrigação ético-profissional ${ }^{(17)}$. O direito do usuário da saúde engloba ainda ser informado sobre os procedimentos, diagnósticos e terapêuticos relacionados à saúde, ser identificado e chamado pelo nome, ter atendimento humanizado e acolhedor em um ambiente limpo, confortável, seguro e acessível a todos, ser respeitada a autonomia frente às escolhas ${ }^{(18)}$. Além desses, deve-se atentar para a privacidade das informações, no armazenamento correto e o cuidado da não disponibilização em mídias digitais ${ }^{(21)}$.

Nessa perspectiva, conhecimento, competências e habilidades podem ser apreendidas pela equipe de Enfermagem para garantia dos Direitos Humanos e dos usuários da saúde fundamentadas nos princípios bioéticos e em valores. Para isso, quanto antes o contato dos profissionais e usuários, melhor a orientação para os princípios da bioética e dos $\mathrm{DH}^{(22)}$.

Espera-se que as reflexões das participantes possam subsidiar uma prática que promova o respeito aos Direitos Humanos e o cuidado de qualidade, buscando equidade e universalidade no atendimento aos usuários ao proporcionar sentimentos de satisfação, acolhimento, compreensão e respeito à sua dignidade, além de estimular novas pesquisas sobre a temática, no intuito de analisar as transformações dos Direitos Humanos e sua aplicabilidade na sociedade moderna.

Dessa forma, este estudo possibilitou a compreensão das profissionais de Enfermagem em relação aos Direitos Humanos e sua garantia no atendimento aos usuários em serviços de emergência, fundamentado em normativas como a Constituição Federal da República, a Declaração Universal dos Direitos Humanos e a Carta de Direitos dos Usuários da Saúde, o que converge com as responsabilidades dessas profissionais no cuidado aos usuários que têm buscado estratégias de concretização desses direitos.

Destarte, como limitação deste estudo tem-se o local, pois diante da diversidade e da complexidade do cenário hospitalar, esta compreensão não retrata o desvelar das vivências de profissionais sobre Direitos Humanos em outros setores, além da emergência.

\section{Conclusão}

A compreensão das Enfermeiras e Técnicas participantes deste estudo sobre Direitos Humanos está estruturada no respeito aos direitos 
sociais contidos na Declaração Universal dos Direitos Humanos, na Constituição Federal do Brasil e na Carta de Direitos dos Usuários da Saúde, e compreendem os Direitos Humanos como leis que garantem benefícios ao mais necessitados.

Não obstante compreenderem os Direitos Humanos como direito social contido em normativas nacionais e internacionais, as profissionais de Enfermagem fundamentam a compreensão sobre tais direitos em princípios bioéticos e valores essenciais, para a garantia e o respeito aos Direitos Humanos durante a prestação de cuidados. Assim, ao compreender sobre Direitos Humanos, as profissionais deste estudo conseguem assegurar o cuidado digno e humano aos usuários da saúde que buscam atendimento em unidade de emergência hospitalar.

O estudo desvela a presença inerente nas profissionais dos aspectos bioéticos, como a beneficência, autonomia, alteridade, privacidade, respeito à identidade pessoal, o direito à informação, que são essenciais e contribuem para as mudanças necessárias no agir profissional, a fim de favorecer o alcance dos Direitos Humanos a todas as pessoas que necessitam de atendimento à saúde.

\section{Contribuições:}

1 - concepção, projeto, análise e interpretação dos dados: Tyciana Paolilo Borges e Darci de Oliveira Santa-Rosa;

2 - redação do artigo e revisão crítica relevante do conteúdo intelectual: Tyciana Paolilo Borges, Karla Ferraz dos Anjos, Julia Barbosa de Magalhães, Renata da Silva Schulz e Darci de Oliveira Santa-Rosa;

3 - aprovação final da versão a ser publicada: Tyciana Paolilo Borges e Karla Ferraz dos Anjos.

\section{Referências}

1. Organização das Nações Unidas. Declaração Universal dos Direitos Humanos [Internet]. Nova York (EUA); 1948 [cited 2020 Aug 19]. Available from: http://www.un.org/en/documents/udhr/ index.shtml
2. Brasil. Senado Federal. Constituição da República Federativa do Brasil [Internet]. Brasília (DF): 1988 [cited 2020 Aug 19]. Available from: https://www2. senado.leg.br/bdsf/bitstream/handle/id/518231/ CF88_Livro_EC91_2016.pdf?sequence=1

3. International Council of Nurses. The ICN Code of Ethics for Nurses [Internet]. Geneva (CHE): 2012 [cited 2020 Aug 18]. Available from: https://www. icn.ch/sites/default/files/inline-files/2012_ICN_ Codeofethicsfornurses_\%20eng.pdf

4. Ventura CAA, Mendes IAC, Godoy S, Fumincelli L, Souza MC, Souza Junior VD. Perceptions of brazilian nursing faculty members regarding literacy of human rights related to health in nursing undergraduate programs. BMC Int Health Hum Rights. 2019;19(27). DOI: 10.1186/ s12914-019-0213-7

5. Maffacciolli R, Oliveira DLLC. Challenges and perspectives of nursing care to vulnerable populations. Rev Gaúcha Enferm. 2018;39:e20170189. DOI: 10.1590/1983-1447.2018. 20170189 Portuguese

6. Burkholder TW, Hill K, Hynes EJC. Developing emergency care systems: a human rights-based approach. Bull World Health Organ. 2019;97(9):612-9. DOI: 10.2471/BLT.18.226605

7. Simões A, Sapeta P. The concept of dignity in nursing care: a theoretical analysis of the ethics of care. Rev bioét. 2019;27(2):244:52. DOI: 10.1590/1983-80422019272306 Portuguese

8. Polit DF, Beck CT, Hungler BP. Compreensão do delineamento da pesquisa qualitativa. In: Polit DF, Beck CT, Hungler BP. Fundamentos da pesquisa em enfermagem: métodos, avaliação e utilização. 5 a ed. Porto Alegre: Artmed; 2004. p. 199-221.

9. Gil AC. Métodos das ciências sociais. In: Gil AC. Métodos e técnicas de pesquisa social. 6a ed. São Paulo: Atlas; 2008. p. 8-25.

10. Vietta EP. Configuração triádica, humanistaexistencial-personalista: uma abordagem teóricametodológica de aplicação nas pesquisas de enfermagem psiquiátrica e saúde mental. Rev Latino-Am Enfermagem [Internet]. 1995;3(1):31-43. DOI: 10.1590/S0104-11691995000100004

11. Organização das Nações Unidas para a Educação, a Ciência e a Cultura. Declaração universal sobre bioética e direitos humanos [Internet]. Lisboa (PRT): Unesco; 2005 [cited 2020 Aug 18]. Available from: http://unesdoc.unesco.org/ images/0014/001461/146180por.pdf 
12. Brasil. Ministério da Saúde. Carta dos Direitos dos Usuários da Saúde [Internet]. 3a ed. Brasília (DF); 2011 [cited 2020 Aug 19]. Available from: http:// bvsms.saude.gov.br/bvs/publicacoes/cartas_ direitos_usuarios_saude_3ed.pdf

13. Brasil. Conselho Nacional de Saúde. Resolução n. 466/2012, de 12 de dezembro de 2012. Dispõe sobre as diretrizes e normas da pesquisa envolvendo seres humanos [Internet]. Brasília (DF); 2012 [cited 2014 Jun 10]. Available from: https://conselho.saude.gov.br/resolucoes/2012/ Reso466.pdf

14. Oliveira MHB, Vianna MB, Telles N, Machado FRS, Ferreira AP, Telles FSP, et al. Direitos humanos e saúde: 70 anos após a Declaração Universal dos Direitos Humanos. RECIIS (Online). 2018;12(4):370-4. DOI: 10.29397/ reciis.v12i4.1667

15. Organização das Nações Unidas. O que são direitos humanos? [Internet]. Brasília (DF); 2020 [cited 2020 Aug 19]. Available from: https://nacoesunidas.org/ direitoshumanos/

16. Ventura CAA, Moraes VCO, Jorge MS. Human rights of people with mental disorders: health professionals' and clients' views. Rev enferm UERJ. 2017;25:1-6. DOI: 10.12957/reuerj.2017.4344 Portuguese

17. Conselho Federal de Enfermagem. Código de Ética dos Profissionais de Enfermagem [Internet]. Brasília (DF): 2017 [cited 2020 Aug 18]. Available from: http://biblioteca.cofen.gov.br/wp-content/ uploads/2019/11/C\%C3\%B3digo-de-\%C3\%89ticados-profissionais-de-Enfermagem.pdf

18. Brasil. Conselho Nacional de Saúde. Resolução n. 553, de 9 de agosto de 2017. Aprova a atualização da Carta dos Direitos e Deveres da Pessoa Usuária da Saúde que dispõe sobre as diretrizes dos Direitos e Deveres da Pessoa Usuária da Saúde anexa a esta Resolução [Internet]. Diário Oficial da União. Brasília (DF); 2018 [cited 2020 Aug 18]. Available from: http://conselho.saude. gov.br/resolucoes/2017/Reso553.pdf

19. Figueiredo AM. Bioethics: criticism of principialism, Brazilian Constitution and principle of human dignity. Rev bioét. 2018;2(4):494-505. DOI: 10.1590/1983-80422018264267

20. American Nurses Association. Center for Ethics and Human Rights. The Nurse's Role in Ethics and Human Rights: Protecting and Promoting Individual Worth, Dignity, and Human Rights in Practice Settings [Internet]. Georgia (EUA); 2016 [cited 2020 Aug 19]. Available from: https://www. nursingworld.org/ 4af078/globalassets/docs/ana/ ethics/ethics-and-human-rights-protecting-andpromoting-final-formatted-20161130.pdf

21. Carvalhal GF, Poli MH, Clementel FK, Gauer GC, Marques GH, Silveira IG, et al. Recommendations for the protection of patient privacy. Rev bioét. 2017;25(1):39-43. DOI: 10.1590/198380422017251164 Portuguese

22. Costa RRO, Medeiros SM, Martins JCA, Coutinho VRD. Simulação no ensino de enfermagem: reflexões e justificativas a luz da bioética e dos direitos humanos. Acta bioeth. 2018;24(1):31-8. DOI: 10.4067/S1726569X2018000100031

Recebido: 19 de agosto de 2020 Aprovado: 29 de setembro de 2020

Publicado: 26 de novembro de 2020

A Revista Baiana de Enfermagem utiliza a Licença Creative Commons - Atribuição-NãoComercial 4.0 Internacional. https://creativecommons.org/licenses/by-nc/4.0/

Este artigo é de acesso aberto distribuído sob os termos da Licença Creative Commons (CC BY-NC). Esta licença permite que outros remixem, adaptem e criem a partir do seu trabalho para fins não comerciais. Embora os novos trabalhos tenham de lhe atribuir o devido crédito e não possam ser usados para fins comerciais, os usuários não têm de licenciar esses trabalhos derivados sob os mesmos termos. 